\title{
MOVILIDAD SOCIAL ESPACIAL EN LOS ASENTAMIENTOS INFORMALES DE BUENOS AIRES
}

\author{
Jean-Louis van Gelder \\ María Cristina Cravino \\ Fernando Ostuni
}

\begin{abstract}
RESUMO Como na maioria das cidades da América Latina, uma das formas de acesso central à terra è habitação para os setores populares em Buenos Aires é através da criação de assentamentos informais. Este artigo analisa o desenvolvimento da informalidade urbana, os padröes de mobilidade social e trajetórias residenciais em empreendimentos informais e na Área Metropolitana de Buenos Aires, durante as últimas décadas. Usando a informação quantitativa (gerada com pesquisas próprias) e as informaçôes qualitativas (obtidas através de entrevistas em profundidade, complementadas pela observação de campo), pretendese mostrar a existência de uma variedade considerável nas perspectivas e estratégias que os atores usam para construir a posse segura de sua casas. Nesta base, além disso, o texto discute como as politicas públicas e marcos legais constituem não só uma condição para o desenvolvimento da informalidade como um fenômeno, mas até mesmo influenciar a forma e as características adquiridas.
\end{abstract}

P A L A V R A S - C H A V E : assentamentos informais; mobilidade social; movilidad residencial; Buenos Aires; politica pública.

\section{INTRODUCCIÓN}

La intención de este artículo es mostrar las diferentes lógicas de crecimiento entre las dos modalidades más importantes de urbanizaciones informales del Área Metropolitana de Buenos Aires: los "asentamientos" y las "villas". ${ }^{1}$ Tomando como punto de partida el surgimiento de cada una de estas tipologías en relación con su contexto histórico, social y económico, desde hace décadas coexisten y presentan nuevas características en relación con la dinámica social que les dio origen. De este modo, analizar en perspectiva las diferencias y continuidades en la población que habita en uno y otro tipo de barrio, a partir de ciertos ejes transversales, puede contribuir a arrojar luz sobre los cambios acontecidos no sólo en las características de una y otra, sino del hábitat popular metropolitano.

En las primeras dos secciones partimos de reconstruir en proceso que dio origen a cada una de esas formas, haciendo hincapié en la dinámica social y económica general, pero también atendiendo a las acciones estatales específicas que incidieron en las posibilidades de acceso al suelo y a la vivienda. Luego, identificamos algunas de las características predominantes en los barrios informales del AMBA en la actualidad, a partir de su desarrollo durante las últimas dos décadas. Sobre esa base, analizamos en 
forma transversal ciertos aspectos que permiten observar las continuidades y rupturas entre los residentes de las villas y los asentamientos partiendo de un conjunto de interrogantes que nos permiten identificar las dinámica actual en la movilidad social y espacial en cada uno de estos barrios: cómo incide la localización en los habitantes de los asentamientos informales, cuáles son las motivaciones para permanecer o cambiar de lugar de residencia, qué importancia se asigna a la perspectiva de formalizar la situación legal en cuanto a la tenencia de la vivienda, qué diferencias se observan en las trayectorias habitacionales de los residentes en villas y en asentamientos, y cómo problematizan a relación entre el barrio y "el afuera" en cada lugar. Estos puntos son abordados a partir de análisis de dos encuestas y de una serie de entrevistas en profundidad, realizadas en diferentes "villas" y "asentamientos" del AMBA. Finalmente, presentaremos algunas reflexiones que, lejos de intentar presentar conclusiones taxativas, intentan abrir interrogantes y realizar aportes al debate público en torno al problema del acceso a la vivienda y del derecho a la ciudad.

\section{LAS “VILLAS": SURGIMIENTO Y DESARROLLO HISTÓRICO}

Desde fines del Siglo XIX hasta la década del 40, los migrantes que provenían de Europa y llegan a Buenos Aires se hospedaban en cuartos de los llamados "conventillos" (inmuebles con varias habitaciones, donde los residentes compartían instalaciones como el baño y la cocina y un patio común), pagando alquileres elevados en condiciones de hacinamiento. Esta modalidad fue desapareciendo por que las autoridades adoptaron políticas urbanas higienistas combinadas con represivas, ya que tanto se quería evitar la propagación de enfermedades como la tuberculosis o cólera como impedir que se transmitieran ideologías de izquierda entre los trabajadores que habitaban allí. Ante la crisis mundial de 1930 y la expansión masiva de la desocupación, muchos trabajadores migrantes no podían pagar un alquiler y se asentaron en construcciones precarias en las áreas centrales de la ciudad e inclusive en vagones de trenes que no funcionaban cerca de las estaciones ferroviarias terminales. Así se fueron conformando las "villas miseria", el segundo término para connotar que se trataba de barrios donde se concentraba la pobreza. Si bien la primera urbanización informal de Buenos Aires data de la década de

2 Existen algunas referencias a pequeñas agrupaciones de viviendas precarias cerca de basurales en la zona sur de la ciudad, pero no llegan a constituir un barrio, a fines del siglo XIX. $1930,{ }^{2}$ es recién a partir de los años '50 que los asentamientos informales, nombrados como las "villas miseria", adquieren relevancia como uno de los emergentes del problema de la vivienda popular. En sus orígenes, las "villas" funcionaban como un espacio habitacional transitorio para los trabajadores inmigrantes europeos en plena crisis mundial. Pero al poco tiempo se pobló de migrantes internos cuando cambió en un contexto debido a la adopción por parte de del Estado de un modelo productivo centrado en la sustitución de importaciones, que derivó en la expansión del mercado interno. A partir de la década del 40, las oportunidades de empleo, en un ciclo de movilidad social ascendente, unido a una legislación permisiva en materias de uso del suelo y a la disponibilidad del mismo a precios accesibles en la periferia, junto a un sistema de transporte subsidiado, aseguraban que la mayoría de los trabajadores migrantes externos o internos pudiese mudarse a una vivienda en condiciones legales al cabo de unos pocos ańos de haber llegado a la ciudad (TORRES, 1975). 
Hacia fines de la década de 1940, la política de sustitución de importaciones llevó a la concentración de las industrias en los alrededores de Buenos Aires y atrajo mano de obra hacia ese territorio, mientras que en las zonas de producción agropecuaria se generaba un proceso de mecanización del campo, que expulsaba mano de obra (TORRES, 1975). Desde fines de la década del 40 hasta principios de los 50 unas 200.000 personas llegaron a Buenos Aires en el marco de este proceso (KEELING, 1996). En consecuencia, entre 1947 y 1960 la población del área conurbana de la Ciudad de Buenos Aires creció más del doble y, a pesar de las políticas habitacionales y del elevado nivel de inversión pública en vivienda social, la creación de nuevas viviendas formales fue sobrepasada por el tamaño de la migración (KEELING, 1996). Las "villas" rápidamente se poblaron de migrantes internos, desapareciendo casi por completo los europeos.

Durante la década del ' 60 , nuevamente se modifica parcialmente el perfil de los habitantes de estos barrios, al llegar un número considerable de población migrante proveniente de países limítrofes, principalmente de Bolivia y Paraguay. Esta fue una de sus formas de lograr un lugar para vivir en la ciudad, manteniéndose la idea de que fuera un lugar transitorio, aunque esa transitoriedad no fuese tal. De esta forma, la "villa" va consolidándose como un tipo de barrio conocido y reconocido por todos los habitantes de la ciudad. Siguiendo a Yujnovsky (1984), la población de los asentamientos informales de Buenos Aires creció en promedio por encima de un $8 \%$ anual entre 1950 y 1970.

En general, las "villas miserias", que luego pasar a ser llamadas simplemente "villas" se ubicaron en terrenos vacantes, predominantemente de propiedad estatal, entrando en conflicto con la normativa urbanística por la forma de la planta urbana y del tipo de construcción que allí se asentaba. Se destacan por contar con una trama irregular, con pasajes angostos y "laberínticos", y condiciones de habitabilidad deficitarias (CRAVINO, 2006). Debido a la falta de presencia de la regulación estatal, los habitantes crearon organizaciones internas para normar la vida cotidiana en los barrios, principalmente para supervisar la distribución de los lotes o fomentar mejoras en el acceso a los servicios públicos en cada uno de los barrios. Curiosamente, la primera organización de vecinos surge a partir de clubes de fútbol fundados por los residentes, los llamados entonces "villeros" (ZICCARDI, 1983). Para comienzos de la década de 1970, estas organizaciones adquirieron gran envergadura trascendiendo a cada uno de los barrios y conformaron lo que se autodenominó "movimiento villero", alcanzando en ese entonces su punto máximo de desarrollo. Esto implicaba la creación de una organización de segundo grado conformada por delegados de diferentes villas que hacían oír sus preocupaciones y demandas hacia el Estado y adquirieron un fuerte nivel de politización, acompañando a la sociedad argentina y contando con la presencia de sacerdotes católicos comprometidos con la Iglesia para el Tercer Mundo.

Este proceso organizativo y participativo fue interrumpido cuando la dictadura militar asumió el gobierno en el año 1976 (permaneciendo hasta 1983) y puso en marcha una política de erradicación de villas en la Capital Federal, generando una fuerte disminución en su cantidad de habitantes que pasó de más de 200.000 personas a poco más de 10.000 a comienzos de la década del '80 (CUENYA, 1993). Con el paso de los años, estos barrios fueron nuevamente repoblados y en la actualidad están alcanzando la misma magnitud que antes de iniciarse dicho proceso de erradicación.

Paralelamente, en la Provincia de Buenos Aires (jurisdicción donde se encuentran 
los municipios conurbanos de la Ciudad de Buenos Aires) en 1977 el gobierno militar promulgó el Decreto ley 8.912 de uso del suelo. Se propuso interrumpir el veloz crecimiento de los loteos populares, la modalidad predominante de acceso formal al suelo urbano para los sectores populares. Esta norma marcaba nuevos estándares y prohibía realizar loteos para usos urbanos sin la infraestructura correspondiente. Dicha medida conllevó un aumento considerable en los precios del suelo e interrumpió la autorización de nuevos parcelamientos y, así, condujo a los sectores populares a la informalidad urbana. Pocos años después de esta medida, surge la modalidad de la ocupación organizada de tierra vacante, conocida como "asentamiento". Éstos se diferenciaban de las villas por mimetizarse a la trama urbana regular y resultar en menor densidad habitacional al establecerse sólo una familia por lote. Tal como las villas, cada grupo familiar autoconstruía su vivienda.

\section{NUEVOS MODOS DE INFORMALIDAD: LA GÉNESIS DEL “ASENTAMIENTO”}

Las leyes y políticas implementadas por la última dictadura militar, junto con las transformaciones económicas promovidas durante este período, crearon una situación en la cual amplios sectores de la población fueron empujados a la pobreza y encontraron un lugar en la periferia de la ciudad, donde se produjeron las primeras ocupaciones de tierras. Estos "asentamientos" presentaban diferencias respecto de las "villas" en una variedad de aspectos. Los asentamientos son el resultado de una ocupación organizada, desarrollada en un momento específico y acotado. Los ocupantes, en general algunos cientos de familias, invaden colectivamente una parcela de tierra vacante pública o privada, sobre la cual construyen velozmente sus primeras viviendas con materiales precarios, las que luego consecutivamente van mejorando o construyendo en firme. Además, los asentamientos difieren de las villas en su forma; las últimas densamente pobladas de manera espontánea, sin ningún patrón prefijado, mientras que los asentamientos presentan una forma urbana definida, con terrenos delimitados en parcelas y el amanzanado rectangular similar al de la ciudad formal, siguiendo así los requerimientos de la normativa urbana. Mientras las villas tienden a estar ubicadas en áreas centrales en la ciudad (capital federal y primer cordón del conurbano bonaerense), los asentamientos predominan en la periferia urbana.

Hay una lógica clara que explica la forma espacial y organizativa que predomina en la conformación de los asentamientos. Por un lado, los primeros asentamientos generaron una estrategia defensiva hacia un Estado hostil, que respondió a su presencia con acciones orientadas hacia su erradicación (MERKLEN, 1997). Comparados con las ocupaciones llevadas a cabo en forma aislada por individuos o grupos familiares solos, las alternativas colectivas y organizadas tenían mejores posibilidades de resistir los intentos de erradicación debido a su visibilidad y organización social. Esto también

3 Esto es, a menudo son terrenos propensos a inundaciones 0 al lado o en vertederos antiguos o tierras que son difícil de explotar comercialmente debido a restricciones legales (CRAVINO, 2001). explica su ubicación en la periferia urbana en tanto hay menos incentivos para reaccionar de parte de los propietarios de los terrenos (ya sean estatales o privados), ya que además por lo general los terrenos no eran aptos para el loteo, debido a estar cercanos a basurales, estar en áreas inundables o simplemente muy alejados de los medios de transporte. ${ }^{3}$ 
Además, a diferencia de las villas, los asentamientos han estado desde sus inicios orientados hacia la regularización de la situación de tenencia del suelo y sus habitantes han intentado activamente obtener su legalidad a través de la organización y gestiones ante el Estado. Este aspecto también permite explicar por qué esta forma de ocupación intenta cumplir con los parámetros establecidos en la legislación de usos del suelo, tales como la dimensión mínima de cada lote y anchos de calle. Difícilmente se trate de una coincidencia el hecho de que casi inmediatamente después de la interrupción de los loteos como resultado de la sanción del Decreto ley 8912 , comenzaran a generarse asentamientos.

En un contexto de represión política y reestructuración económica con una lógica excluyente, la política pública de la última dictadura militar clausuró las opciones habitacionales en las áreas centrales de la ciudad, condicionando así la localización de la nueva informalidad hacia la periferia, mientras que la legislación de uso del suelo sancionada en ese momento inhibía las opciones de tierra formal a precios accesibles, consecuentemente contribuía a la emergencia del fenómeno de las tomas de tierra, influyendo así también en la forma particular o formando la informalidad.

La idea de "no hacer una villa" y "diferenciarnos de la villa" como meta para facilitar la futura regularización dominial y, al mismo tiempo, para mejorar evitar el estigma que conlleva esta forma de habitar en la ciudad. Aun cuando compartan misma situación de estar fuera de la legalidad con las "villas", y alberguen poblaciones con niveles similares de pobreza, en términos de identidad percibida, desde la perspectiva de los residentes el asentamiento debiera ser claramente distinguido de la "villa", aún cuando el resto de la sociedad en general no haga esta distinción. Esto implica que entre las formas legítimas de habitar la ciudad, el "asentamiento" estaría en un estadio más "tolerable" a los actores de poder en la ciudad. En la sección siguiente haremos foco en comparar estos dos tipos de urbanización informal y la influencia atribuible a los modos específicos de desarrollo y organización social propios de cada tipología.

Una característica que resalta respecto de otras ciudades latinoamericanas es que en Buenos Aires, en especial a partir del retorno de la vida democrática -como ya mencionáramos- ha existido una mayor tolerancia a las tomas de tierra. Tal vez por eso la figura del "urbanizador pirata", tan recurrente en ciudades como Bogotá y Rio de Janeiro, es poco común en Buenos Aires (GILBERT; WARD; ABRAMO, 2009; PARIAS; ABRAMO, 2009) y constituye en una forma institucionalizada de acceso al suelo (CRAVINO, 2006).

\section{LOS ASENTAMIENTOS INFORMALES DESDE LA DÉCADA DEL 90 HASTA LA ACTUALIDAD}

Luego del retorno democrático en el año 1983, las acciones represivas contra las ocupaciones ilegales de tierra fueron mermando, estableciéndose un clima de mayor tolerancia. No obstante, esta última variaba sensiblemente dependiendo de la zona donde estuviesen ubicadas las ocupaciones. Debe notarse que pese a la vuelta de la democracia la legislación restrictiva al desarrollo de opciones de acceso a la vivienda para los sectores populares permaneció inalterada, estando vigente en la actualidad (CRAVINO, 1998). 
En 1989 la economía argentina estuvo al borde del colapso, la inflación alcanzó niveles del 5.000 por ciento anual y la economía urbana se redujo a niveles previos a los de 1970 (KEELING, 1996). En este contexto, se adoptaron crudamente los lineamientos del neoliberalismo (bajo la impronta del llamado Consenso de Washington) y se implementó un paquete de reformas presentado como "cirugía mayor sin anestesia”, que incluyó la venta de empresas estatales, la privatización de los servicios públicos, y la desregulación de la actividad económica por parte del sector público (ZANETTA, 2004). Estas políticas dieron pie a la participación de actores internacionales en la provisión de los servicios públicos y en el desarrollo de operaciones inmobiliarias, al tiempo que alentaron la especulación inmobiliaria, intensificaron la comercialización de tierra urbana, empujaron al alza los precios del suelo y, con ello, se observó un incremento importante de la informalidad (CLICHEVSKY, 1999).

En línea con la ideología neoliberal adoptada por el gobierno nacional en la década del '90, se produjo un cambio en la política pública respecto de las tomas de tierra. Se inauguró un programa basado en la transferencia de derechos de propiedad a los asentados en tierras estatales nacionales. Sin embargo, los avances en la implementación de estas normas fueron reducidos y los desalojos en los asentamientos informales, especialmente los más recientes, resultaron ilustrativos respecto de la ausencia de una política integral de tierras urbanas en la Argentina.

Para mantener la estabilidad macroeconómica, el gobierno federal recurrió al financiamiento internacional y el país enfrentó un proceso de creciente endeudamiento externo. En 1998, la deuda era equivalente a más del 400\% de las exportaciones anuales. La economía disminuyó y entró en recesión. En el cambio de milenio, la protesta social explotó con manifestaciones frente a las sedes de los poderes ejecutivo y legislativo, cortes de rutas y puentes en áreas centrales de Buenos Aires y saqueos a supermercados. En Diciembre de 2001, Argentina declaró el default -el más importante en la historia del mundo- sobre su deuda externa y hacia 2002 más de la mitad de la población se encontraba por debajo de la línea de pobreza.

Desde 2003 en país ha ido recuperando un crecimiento anual a razón de un $8 \%$ entre 2003 y 2008 (INDEC, 2009). Hacia 2005, el gobierno reestructuró su deuda externa y canceló sus compromisos con el FMI. En los años recientes los niveles de desempleo disminuyeron en forma significativa. Junto con este cambio de escenario, se produjo un boom en el sector inmobiliario que condujo a fuertes subas en los precios, generando crecientes dificultades para el acceso al mercado inmobiliario formal para las personas de bajos ingresos. A pesar de las políticas neo-keynesianas, el mercado de suelo y viviendas permanece fuera de su alcance y continúa siendo escasamente regulado. El crecimiento del sector agropecuario (en particular el vinculado a la exportación de soja) generó un excedente, que en buena medida fue volcado al sector inmobiliario como "inversiones seguras" y conservadoras en un escenario de post crisis, contribuyendo a generar un movimiento de alza de precios.

En el año 2004 hubo un fuerte impulso a las políticas habitacionales para sectores de bajos ingresos, materializado en la creación del Programa Federal de Construcción de viviendas. El objetivo del programa era construir 38.000 viviendas en el Área Metropolitana de Buenos Aires en el primer año, lo que implicaba un cambio de escala diez veces mayor al de cualquier otra política pública de vivienda en los quince años precedentes (OSTUNI, 2007). En 2006, se anunció la segunda etapa del programa, que fijaba como meta construir otras 75.000 viviendas en el AMBA. A 
pesar de que estas metas físicas implicaron un punto de partida importante cuando se lo compara con la escala de los programas previos, el Programa Federal presenta algunos inconvenientes: por un lado, retrasos en su ejecución efectiva; por el otro, respecto de la ubicación de las viviendas, en general éstas en su mayoría se encuentran alejadas de las áreas centrales y dinámicas para obtener ingresos, reforzando el patrón de segregación residencial. Según datos oficiales entre el año 2003 y el 2012 se efectuaron en la Provincia de Buenos Aires 177.782 soluciones habitacionales (viviendas nuevas y mejoramientos). El Programa de Urbanización de villas y asentamientos precarios construyó en el año 2005 y 2012 construyeron 35.829 viviendas en el Gran Buenos Aires (menos unas pocas en otras localidades).

Consecuentemente, a pesar de las tasas de crecimiento económico, de la existencia de legislación que habilita la regularización dominial en barrios informales, de un gasto público considerable en vivienda social, la informalidad sigue creciendo. Si tomamos los datos más recientes (CRAVINO, 2008c), el Área Metropolitana de Buenos Aires tiene alrededor de 800 urbanizaciones informales, donde habitan poco más de un millón de individuos. El Censo de Población y vivienda del 2010 muestra un mejoramiento de las condiciones habitacionales de todo el país (bajando la cantidad de viviendas precarias o con deficiencias) en relación al 2001. En particular, en el Área Metropolitana implica una disminución del 2,8\% de las viviendas deficitarias. También se observa un mejor acceso a los servicios públicos indispensables como el agua corriente que se amplió en un 16,4\%, siendo un 5,4\% en el Conurbano Bonaerense, mientras la población de este aglomerado creció un 23,8\%. No obstante, todo indica que el porcentaje de situaciones de tenencia irregular del suelo no disminuyó, aún cuando no se publicaron los datos correspondientes. Sólo se conoce que la población de villas en la Ciudad Autónoma de Buenos Aires pasó de 107.422 habitantes en 2001 a 163.587 en 2010.

Tabla 1 - Población en villas y asentamientos en el Área Metropolitana de Buenos Aires (AMBA) 2008

\begin{tabular}{lllllll}
\hline \multirow{2}{*}{ Categoría } & \multicolumn{2}{c}{ Capital Federal } & \multicolumn{2}{c}{ Conurbano Bonaerense } & \multicolumn{2}{c}{ AMBA } \\
\cline { 2 - 7 } Villas & Cantidad & $\%$ & Cantidad & $\%$ & Cantidad & $\%$ \\
Asentamientos & 108,011 & $10.5 \%$ & 518,130 & $50.3 \%$ & 626,141 & $60.7 \%$ \\
Total & 0 & $0 \%$ & 404,359 & $39.2 \%$ & 404,359 & $39.3 \%$ \\
\hline
\end{tabular}

Nota: De los 27 asentamientos, que contaban con una población total de 14.365 personas, no pudo ser constatado con exactitud si se trataba de villa o asentamiento (Fuente: CRAVINO, 2008).

A partir de los rasgos salientes expuestos, es pertinente observar con mayor detenimiento las dos formas o tipologías predominantes de urbanización informal en Buenos Aires, las villas y los asentamientos. Intentaremos mostrar que el tipo de urbanización está fuertemente ligado a las características de las políticas públicas, al marco regulatorio y a las transformaciones en el modelo económico. 
4 Los datos en que se basa esta parte del documento se recogieron por medio de la aplicación dos encuestas y entrevistas en profundidad en once barrios informales. Los datos cuantitativos se recogieron en los años 2005 2007 y complementariamente entre los años 2007 y 2009 por los autores del artículo realizaron entrevistas en dichos barrios informales.

\section{DIFERENCIAS ENTRE RESIDENTES DE VILLAS Y ASENTAMIENTOS ${ }^{4}$}

Las dos tipologías presentan ventajas y desventajas la una respecto de la otra. Las "villas", en particular las más antiguas ubicadas en la Capital Federal, suelen estar localizadas en áreas centrales de la ciudad, por lo que se encuentran mejor situadas en términos de oportunidades de empleo y estrategias de reproducción de la vida cotidiana. Esto se ve reflejado en la Tabla 2, en la cual puede observarse que el nivel de desempleo es significativamente más alto en los "asentamientos" estudiados que en las "villas" en las que se desarrollo el relevamiento. Cuando se les pregunta a las personas por las razones para vivir en su barrio, los habitantes de "villas" mencionan la proximidad como motivación principal, seguido de la cercanía con algún familiar como segunda razón. En los "asentamientos" la expansión de la familia es el motivo referido como más importante. En cambio, la proximidad a los lugares de trabajo difícilmente sea mencionada por los asentados, mientras que la expansión de la familia es muy rara vez sugerida por los villeros. A pesar de que en general están ubicados en lugares menos favorables y más distantes de los centros urbanos, los "asentamientos" poseen lotes de mayor tamańo que cuentan con la ventaja de tener más espacio para construir una vivienda que albergue a toda la familia. En las "villas", en cambio, las viviendas son más pequeñas, y es más común encontrar familias enteras compartiendo una única habitación. Las dos tipologías resultan expresivas de necesidades diferentes, al menos parcialmente. Aún así, las dificultades económicas aparecen como un denominador común para ir a vivir a cualquiera de las dos modalidades.

Además, las "villas", en especial aquellas ubicadas en áreas centrales, a menudo tienen un mercado informal de alquileres e incluso un mercado de la vivienda (sin título de propiedad), mientras que en los asentamientos generalmente predomina la tenencia (que los residentes denominan "ser propietarios", aunque en realidad sea una tenencia informal). El mercado de alquileres en las "villas" se ha vuelto muy dinámico, aunque los inquilinos no tienen una cobertura legal equivalente a la de quienes alquilan en el mercado formal; por lo tanto, tienen una muy escasa seguridad en la tenencia. No pagar el alquiler del mes puede llevar a un desalojo inminente (CRAVINO, 2006; 2008b). Esta es la opción para aquellos que no tienen dinero suficiente para la compra de una vivienda o no encuentran oferta de ellas. 
Tabla 2 - Razones principales para mudarse al barrio en villas $(\mathrm{n}=363)$ y asentamientos $(\mathrm{n}=429)$

\begin{tabular}{llllll}
\hline & $\begin{array}{l}\text { Proximidad } \\
\text { del trabajo }\end{array}$ & $\begin{array}{l}\text { Proximidad } \\
\text { de la familia }\end{array}$ & $\begin{array}{l}\text { Dificultadesl } \\
\text { económicas }\end{array}$ & $\begin{array}{l}\text { Crecimiento } \\
\text { de la familia }\end{array}$ & $\begin{array}{c}\text { Previamente } \\
\text { desalojados }\end{array}$ \\
\hline Villas & $26.8 \%$ & $24.8 \%$ & $12.8 \%$ & $4 \%$ & $3.4 \%$ \\
& $2.5 \%$ & $13 \%$ & $20.8 \%$ & $25.6 \%$ & $6.6 \%$ \\
$\begin{array}{l}\text { Asentamientos } \\
\text { Promedio de la }\end{array}$ & $13.1 \%$ & $17.8 \%$ & $16.5 \%$ & $16.6 \%$ & $5.1 \%$ \\
\hline \begin{tabular}{l} 
Muestra \\
\hline
\end{tabular}
\end{tabular}

* Esta categoría incluye a los encuestados que mencionaron no poder pagar el alquiler de su vivienda anterior o la pérdida del empleo como principal motivación (Fuentes: Info-Hábitat 2007; CRAVINO, 2006)

Otra diferencia entre las "villas" de las áreas centrales y los "asentamientos" de la periferia radica en el hecho de que en las primeras el fenómeno de la inmigración proveniente de países limítrofes es más relevante en comparación con los segundos (Tabla 3). Esto último puede ser explicado como consecuencia de la importancia de las redes sociales en los procesos migratorios y cómo estas fuerzas la concentración en determinadas localizaciones de ciertos grupos de origen.

\section{PROPIEDAD Y ASCENSO SOCIAL}

Las motivaciones más recurrentes para buscar y querer la propiedad (tanto en términos formales como informales) es tener seguridad en la tenencia y el deseo de poder dejar algo tangible como herencia a los hijos. La propiedad inmobiliaria además implica acceso a un activo estable que incrementa su valor y prestigio con el tiempo en una sociedad que ofrece muy poco de ambas cosas (VAN GELDER, 2009). En otras palabras, la idea de que la vivienda significa mucho más que el albergue o el activo económico se pone claramente en evidencia en el discurso de los habitantes de los barrios informales de Buenos Aires.

Por lo tanto, una ventaja que presenta el "asentamiento" respecto de la "villa" es el hecho de que ofrece una perspectiva de largo plazo en la cual los residentes puede con el tiempo convertirse en los propietarios legales de sus terrenos y que el asentamiento, en algún momento futuro, puede convertirse en un barrio "normal". Este no es el caso de las "villas", que debido a su estructura y densidad poblacional presenta posibilidades de la urbanización más complejas y llevan décadas con la fisonomía de un barrio informal. 
Tabla 3 - Características de la población en villas $(\mathrm{n}=363)$ y asentamientos $(\mathrm{n}=429)$

\begin{tabular}{llllll}
\hline & Nacionalidad $^{\mathrm{a}}$ & Edad $^{\mathrm{b}}$ & Años $^{\mathrm{c}}$ & Trabajo $^{\mathrm{d}}$ & Ingresos $^{\mathrm{e}}$ \\
\hline Villas & $44.3 \%$ & 36 & 11 & $38.9 \%$ & AR \$ 500 \\
Asentamientos & $27 \%$ & 37 & 9 & $62.8 \%$ & AR\$ 619 \\
Promedio de la muestra & $32.5 \%$ & 37 & 10 & $54.5 \%$ & AR\$ 576 \\
\hline
\end{tabular}

Nota: $\mathrm{a}=$ porcentaje de no nacionales; $\mathrm{b}=$ edad promedio del entrevistado; $\mathrm{c}=$ cantidad promedio de años que vive en el asentamiento; $\mathrm{d}=$ porcentaje de desempleados; $\mathrm{e}=$ Ingreso promedio mensual de los hogares $(5$ pesos argentinos $\approx 1$ US\$ al precio oficial, 8 pesos argentinos $=1$ U\$S al dólar paralelo) (Fuente: Info-Hábitat, 2007; CRAVINO, 2006).

\section{TRAYECTORIAS RESIDENCIALES}

A pesar de que tanto las villas como los asentamientos reúnen una población variada en cuanto a su origen, existen diferencias considerables en las trayectorias residenciales que se observa en cada tipología. Cravino (2008a) muestra que la villa es en general el primer hábitat urbano para los recién llegados a la ciudad. Los procesos migratorios, que a menudo se desarrollan a través de redes familiares o de amigos que introduce a los recién llegados con su nuevo lugar y con las diferentes opciones en términos de estrategias de vida, llevan a los migrantes a asentarse primero en la villa (CRAVINO, 2008). La Tabla 2 muestra que la "proximidad (física) a la familia" es mencionada casi dos veces más por los villeros en comparación con los asentados. Aun cuando los residentes en los asentamientos también pueden presentar diferencias en términos de "origen", muchos de sus residentes suelen expresar que en algún momento previo habitaron en una villa. A menudo el pasaje de la villa al asentamiento es percibido como una mejora significativa en las condiciones de vida de las familias, así como también es presentada como una modalidad de ascenso social. Es decir, existe una asociación entre la valoración del tipo de espacio en que se habita y la condición de estatus social.

Los entrevistados provenientes de una villa que llegaron a vivir en un asentamiento perciben que este cambio implicó una mejora en sus condiciones habitacionales pero un deterioro en cuanto a la localización. Además, en las respuestas registradas se observa una mayor incertidumbre en las villas respecto de la seguridad de tenencia en comparación con los asentamientos. Esto revela el dilema entre elegir vivir en la periferia pero con mayor espacio que puede ser utilizado para construir inclusive viviendas para las nuevas generaciones versus una mejor ubicación, es decir estar más cerca de las oportunidades de empleo, pero vivir en espacios reducidos, o lo que es lo mismo en una o dos habitaciones una familia entera, con incertidumbre en la tenencia.

El hecho de que las tomas de tierra hayan sido llevadas a cabo en forma predominante por familias jóvenes de la ciudad que no podían resolver sus necesidades de vivienda es un indicador de que este tipo de informalidad es resultado de las dificultades de una población urbana empobrecida frente a una legislación de uso del suelo y a una política que va en detrimento de sus necesidades de vivienda. En otras palabras, se puede decir que la ley y las políticas públicas condicionaron las opciones habitaciones de una parte de los sectores populares y, por lo tanto, que fueron codeterminantes de las acciones ilegales de los ciudadanos. 
En un sentido, los asentamientos son la expresión de una movilidad social y espacial y de la agencia de los sectores populares en Buenos Aires. Constituyen una estrategia de inconformidad hacia el Estado a través de procesos de movilización y organización social, en los cuales los sectores populares intentan ganar un lugar en la ciudad que algún sentido siempre los ha rechazado. No obstante, a pesar de la inconformidad, el asentamiento se adapta constantemente al sistema legal. Por ejemplo, el asentamiento intenta evitar contravenir la legislación de uso del suelo todo lo posible y mantener las consecuencias de la violación al derecho de propiedad al mínimo (VAN GELDER, 2010). Al mismo tiempo esta conformación urbana alejaría a sus habitantes del fantasma del estigma de la villa, situación que por lo general no sucede. Esto también debe comprenderse tomando en cuenta que existe experiencia conocida donde el Estado toleró ocupaciones, regularizando a posterior su situación o por lo menos comenzando este proceso. Esto implica que se va institucionalizando como una forma legítima aunque ilegal de acceso a la ciudad (CRAVINO, 2008b).

\section{EL ADENTRO VERSUS EL AFUERA: LOS ASENTAMIENTOS INFÓRMALES Y LA SOCIEDAD}

Así, hay un claro límite en la villa que la delimita del resto de la sociedad: el adentro y el afuera del barrio. En el caso de los asentamientos este borde es aún más prominente en términos simbólicos que en el sentido físico, dado que el barrio puede parecer pobre, pero formal. En este sentido los límites espaciales de un barrio operan como un mecanismo unificador, como consecuencia de compartir situaciones de vida e identidades. No obstante, si se observa más de cerca a las relaciones sociales dentro de los barrios, puede percibirse que existe una gran variedad en las respuestas de individuos en situaciones similares respecto de las formas de hacer frente a su condición urbana, así como también entre las villas y los asentamientos en general.

El mito de que los residentes de asentamientos informales se manejan fuera de la ley y son capaces de atentar contra el sistema se ha instalado con una fuerza nada desdeńable. La idea de que "pobres" o "informales" conforman un grupo homogéneo todavía aparece con mucha fuerza, sin duda de manera errónea. Una modalidad de distinción dentro de los barrios que aparece como importante tanto entre residentes de villas como de asentamientos es su creencia en la posibilidad de asenso social y la convicción de que es posible mejorar su situación (CRAVINO, 2008a). Esta creencia conlleva una diferencia en la actitud y en la conducta reflejada por ejemplo en la inversión en mejorar la vivienda en la planificación de largo plazo. Por ejemplo, hemos encontrado familias que envían sus hijos a escuelas privadas mientras habitan en viviendas muy precarias. Este tipo de actitud es muy común entre inmigrantes del Paraguay y de Bolivia para quienes vivir en un asentamiento informal en Buenos Aires no representa retroceder un escalón, sino que ofrece una ventana de oportunidades respecto de la calidad de vida y los servicios (ej. los servicios de salud y educación gratuitos) que son severamente restringidos en sus países de origen (CRAVINO, 2008a). Para muchos residentes argentinos empobrecidos que gradualmente o de repente perdieron su estatus de clase media durante los últimos ańos a menudo se percibe una pérdida de fe en la idea de asenso social. En otras palabras, la idea de que la villa es el lugar donde se aglutina la pobreza no hace justicia a la variedad de trayectorias y estrategias de los residentes. 
5 Entrevista con residentes en el asentamiento 3 de Mayo, Julio de 2005.
Difícilmente cuestiones como la criminalidad, la inseguridad y la violencia no sean mencionadas en las conversaciones con los vecinos. Todos resaltan lo difícil que es vivir en el barrio. No obstante, al mismo tiempo, y paradójicamente a primera vista, muchos pobladores manifiestan haberse arraigado a sus barrios con el correr de los años, y expresan reparos sobre la posibilidad de considerar alternativas habitacionales diferentes de su lugar de residencia. Ante la pregunta de si evaluaría la posibilidad de mudarse de su casa en un asentamiento a un terreno legal, una residente respondió: "moriríamos en nuestras casas antes de ir a otro lado". En el asentamiento más que en la villa, la relación entre solidaridad entre los vecinos, la lucha (conjunta) por su terreno y sus esfuerzos en construir tanto sus viviendas como su barrio, que además de económicos son esfuerzos de carácter emotivo y físico, son elementos que ligan a los habitantes a sus barrios, y esa ligazón aumenta con su desarrollo: "lo que me mantiene en este barrio [...] es que vivo en mi casa, es mía, es que estoy en lo mío, es por lo que luché y lo que me ha costado lágrimas, lágrimas y... lagrimas." ${ }^{5}$

En general, ni la unidad (barrio) ni la fragmentación cristalizan como el paradigma central en el discurso de los residentes y la noción de la identidad del villero (o asentado) juega un rol contradictorio en los asentamientos informales (CRAVINO, 2008a). Por un lado puede ser fuente de orgullo, pero por el otro la discriminación y la estigmatización del resto de la sociedad son sentidas con fuerza (VAN GELDER, OSTUNI; ENDRESS, 2005). Auyero (2005) remarca que ni bien hay una conversación sobre (in)seguridad en Argentina que evita mencionar la "villa", y que los "villeros", una etiqueta que es igualmente aplicada a las personas que vives en barrios pobres, independientemente de si residen en barrios informales o no, son percibidos como una amenaza a ser evitada. Vivir en un barrio informal puede atrincherar la pobreza y limitar el asenso social restringiendo las opciones económicas de los pobladores, pues con la mera mención a vivir en la villa pueden perjudicar sus opciones de obtener un trabajo formal. Hay casos en los que la gente alquila una dirección postal fuera de su barrio para ocultar el hecho de vivir en una villa. Debe destacarse que designarse ellos mismos como "ilegales" ubica a los habitantes de asentamientos informales en una posición desfavorable porque con ello el estado puede justificar tanto las acciones hostiles (ej. intentos de desalojo) como legitimar su ausencia como marco regulador y negar acceso a sus recursos.

\section{CONCLUSIONES}

Este artículo ha intentado mostrar de qué modo la ley, las políticas y el desarrollo socioeconómico han llevado no sólo a la emergencia de los barrios informales en Buenos Aires, sino que también han influido en su forma y ubicación. A pesar de ser idénticos en términos de su estatus (i)legal, de los recursos y características socioeconómicas de su población, así como de otras características, forma y ubicación, en cambio, llevaron al desarrollo de importantes diferencias entre ellos y determinaron patrones de desarrollo. Por ejemplo, los asentamientos tienden a formar una solución habitacional de carácter más permanente y similares al barrio formal, al que aspiran convertirse, a diferencia de una estrategia habitacional transitoria como la de las villas en sus orígenes (CRAVINO, 1998), aunque en la actualidad esa transitoriedad haya perdido peso también en las villas. En estos últimos barrios la condición de "ilegalidad" tiene mayor peso como estigma. En la villa, el ascenso social puede implicar un cambio de situación, pasar de ser inquilino a ser 
propietario o, en algún caso, mudarse a un asentamiento. En estos últimos, el mejoramiento pasa fundamentalmente por la condición de la vivienda, es decir, por la posibilidad de invertir en ella y presionar al Estado para alcanzar la regularización dominial; el objetivo último es la legalización. Por lo cual es una forma de acceso a la ciudad que apela a la institucionalidad y a su reconocimiento a partir de la legalización de su existencia, que implica múltiples pasos para llegar la formalidad (con las incertidumbres que ello acarrea).

En Buenos Aires se ha vuelto claro con los ańos que si va a abordarse seriamente la cuestión de la informalidad en la vivienda es ineludible que la problemática adquiera mayor peso en la agenda pública, lo que requiere una presión considerable desde la base. Fernandes (2007) sostiene que en diversos países de América Latina académicos, políticos, movimientos sociales urbanos y ONGs han entendido gradualmente el hecho de que no hay vía a la reforma urbana posible sin una profunda reforma legal y política y una creciente conciencia pública de los derechos ciudadanos como derechos constitucionales, el derecho a la vivienda y los derechos a los servicios básicos e infraestructura así como también de las obligaciones, en particular de las obligaciones como contribuyente y consumidores. En particular en la Argentina, que no tiene en su Constitución la función social de la propiedad y diferentes debate sobre el Código Civil parecen reticentes a modificar el estatus absoluto de la propiedad. Mientras que en algunos países los movimientos populares han sido capaces de acumular fuerzas durante más de dos décadas presionando por una reforma urbana, en la Argentina los contornos de ese tipo de expresiones han apenas comenzado a emerger en los últimos años. Pero el hecho de que están ahí y adquiriendo peso es un signo positivo para el futuro. Recientemente, en Octubre de 2008, la legislatura de la Provincia de Buenos Aires declaró el estado de emergencia en la provincia con respecto a cuestiones de tierra y vivienda, lo que es un signo de que la informalidad va ganando importancia en la agenda pública. La discusión sobre la urbanización de asentamientos informales incluye cómo hacer este proceso, si construyendo un nuevo barrio o respetando las prácticas de las estrategias de los sectores populares en relación al hábitat y, por lo tanto, apostando por la radicación en el lugar. Un debate similar comienza a generarse en la Ciudad de Buenos Aires en torno a la urbanización de la villa más antigua de la ciudad. Sin embargo, estas políticas no resuelven las causas de la informalidad.

\section{REFERÊNCIAS BIBLIOGRÁFICAS}

ABRAMO, P. (coord.). Favela e mercado informal: a nova porta de entrada dos pobres nas cidades brasileiras. IPPUR, Rio de Janeiro, 2009.

AUYERO, J. Protest in contemporary Argentina: a contentious repertoire in the making. In: FERNÁNDEZ-KELLY, P.; SHEFNER, J. (eds.). Out of the shadows: Political action and the informal economy in Latin America. University Park, PA, Pennsylvania State University Press, 2005. CLICHEVSKY, N. Politicas de regularización en Argentina: entre la euforia y la frustración. Buenos Aires, 1999. (mimeo.).

CRAVINO, M. C. Los asentamientos del Gran Buenos Aires: reivindicaciones y contradicciones. In: M. R. NEUFELD (Ed.). Antropología social y politica. Hegemonia y poder: un mundo en movimiento. Buenos Aires, Eudeba, 1998.

CRAVINO, M. C. La propiedad de la tierra como un proceso: Estudio comparativo de casos en ocupaciones de tierras en el Area Metropolitana de Buenos Aires, Land Tenure Issues in Latin America SLAS Conference. Birmingham, april $6^{\text {th }}-8^{\text {th }}, 2001$.
Jean-Louis van Gelder é investigador do Netherlands Institute for the Study of Crime and Law Enforcement. Doctor en Derecho Universidad de Amsterdam. E-mail: $<j$ lvangelder@gmail.com>.

María Cristina Cravino é Investigadora CONICET-Universidad Nacional de General Sarmiento. Doctora en Antropología. E-mail: <mariacristinacravino@yahoo.com.ar>.

Fernando Ostuni é investigador do Instituto Gino Germani de la Facultad de Ciencias Sociales de la Universidad de Buenos Aires. Magister en Administración Pública. E-mail: <fostuni@hotmail.com>. 
CRAVINO, M. C. Las villas de la ciudad: mercado e informalidad urbana. Buenos Aires: UNGS, 2006.

CRAVINO, M. C. Vivir en la villa. UNGS Los Polvorines, 2008a.

CRAVINO, M. C. Territorialidades en las villas de la Ciudad de Buenos Aires. Estado, Mercado y relaciones sociales de la espacialidad barrial. In: CATENAZZI et al. El retorno de lo politico a la cuestión urbana. Buenos Aires, UNGS, Prometeo, Polvorines, 2008b.

CRAVINO, M. C. (org.). Los mil barrios (in)formales. Aportes para la construcción de un observatorio del hábitat popular del Área Metropolitana de Buenos Aires. Buenos Aires, UNGS, Los Polvorines, 2008c.

CUENYA, B. Programa de radicación e integración de villas y barrios carenciados de la Capital Federal. Buenos Aires, 1993. (mimeo.).

FERNANDES, E. Constructing the "Right to the City" in Brazil. Social and Legal Studies, 16, 2007.

FERNÁNDEZ WAGNER, R. Politica habitacional Argentina: Las contradicciones entre la construcción masiva de viviendas y la real dimensión de las demandas sociales. Buenos Aires, 2006. (mimeo.).

FIDEL, C. Orientación y peculiaridades de la política económica, social y habitacional en la Argentina. La década del 90. In: CUENYA, B.; FIDEL, C.; HERZER, H. (eds.). Fragmentos sociales. Problemas urbanos en la Argentina. Buenos Aires, Siglo Veintiuno Editores, 2006.

INDEC. Instituto Nacional de Estadísticas y Censos. Censo Nacional de Población, Hogares y Viviendas, 2001. www.indec.mecon.ar.

INFO-HÁBITAT. Análisis georreferenciado para el seguimiento de las nuevas intervenciones públicas en hábitat, en el Área Metropolitana de Buenos Aires: Informe Final. Buenos Aires, Universidad Nacional de General Sarmiento, 2007.

KEELING, D. J. Buenos Aires: Global dreams, local crises. Chichester, Wiley, 1996.

MERKLEN, D. Un pobre es un pobre. La sociabilidad en el barrio: entre las condiciones y las prácticas. Sociedad, 11, pp. 21-64, 1997.

OSTUNI, F. Del Fonavi al Federal: Transformaciones socio-urbanas y respuestas estatales. Algunas reflexiones sobre la politica habitational. Centro de Documentación en Políticas Sociales. Documento No 38, 2007.

PARIAS, A.; ABRAMO, P. (2009). Mercado informal de suelo en los barrios populares de Bogotá. Claves para entender el crecimiento de la metrópole. En: ABRAMO, P. (coord.). Favela e mercado informal: a nova porta de entrada dos pobres nas cidades brasileiras. Rio de Janeiro, IPPUR, 2009.

TORRES, H. Evolución de los proceses de estructuración especial urbana. El caso de Buenos Aires. Desarrollo Económico, 15, 281-306, 1975.

VAN GELDER, J. L. Legal tenure security, perceived tenure security and housing improvement. In: Buenos Aires: an attempt towards integration. International Journal of Urban and Regional Research, 33, 126-146, 2009.

VAN GELDER, J. L.; OSTUNI, F.; ENDRES, T. Estar 'en el aire': Seguridad en la tenencia e inversion en el hogar en cinco barrios informales de Buenos Aires. Medio Ambiente y Urbanización, 62, 175-189, 2005.

YUJNOVSKI, O. Claves politicas del problema habitacional Argentino: 1955-1981. Buenos Aires, Grupo Editorial Latinoamericano, 1984.

ZANETTA, C. The influence of the World Bank on national housing and urban policies: the case of Mexico and Argentina during the 1990s. Aldershot, Ashgate Publishing, 2004.

ZICCARDI, A. Villas miseria y favelas: sobre las relaciones entre las instituciones del Estado y la organización social en las democracias de los años sesenta. Revista Mexicana de Sociología, $15,45-67,1983$. 
A B S T R A C T As in most Latin American cities, in Buenos Aires one of the most usual ways low income families can access to land and housing is through the creation of informal settlements. This article examines the development of urban informality, patterns of social mobility and residential trajectories into and between informal settlements in the Metropolitan Area of Buenos Aires during the last decades. Using quantitative information (generated with own surveys) and qualitative (obtained through in-depth interviews, supplemented by field observation) we intend to show the existence of a considerable variety in the perspectives and strategies that social actors use to build tenure security of their homes. On this basis, additionally the text discusses how public policies and legal frameworks not only constitute a condition for the development of informality as a phenomenon, but even influence the shape and characteristics acquired.

K E Y W O R D S : informal settlements; social mobility; residential paths; Buenos Aires; public policy. 